\title{
Creation of a complex electronic map of agriculture and agro-geo databases using GIS techniques
}

\author{
Rustam Oymatov ${ }^{1, *}$ and Sanjarbek Safayev ${ }^{2}$ \\ ${ }^{1}$ Tashkent Institute of Irrigation and Agricultural Mechanization Engineers, Kari Niyazi str., 39, \\ Tashkent, 100000, Uzbekistan \\ ${ }^{2}$ State Scientific Research and Design Institute on Land Management "Uzdavyerloyiha", Choponota \\ str., Chilanzar-C massif, Tashkent, 100097, Uzbekistan
}

\begin{abstract}
This article is devoted to the creation of complex electronic maps of agriculture and agro-geo databases on the basis of geoformation systems (GIS) and technologies. Scientific and practical research on the mapping of the agricultural sector conducted by scientists from foreign countries, the Commonwealth of Independent States and Uzbekistan. Analyzing the research on the classification of agricultural maps, the classification of agricultural maps for the Republic of Uzbekistan is proposed. Content elements of maps covering agricultural sectors and infrastructure objects have been developed by studying topo geodesic, field research, statistical data and classification of agricultural maps. Analyzing the scientific and applied research work on the creation of maps of the studied area, a technological system for creating an electronic map of agriculture using GIS and technologies was developed. This technological system involves the initial data collection, software selection, thematic layer development, conditional character processing, printing, and other processes in creating an agricultural map. A technological system for creating an agro-geo databases has been developed using the proposed content elements, topographic and geodetic works, statistical data and the capabilities of GIS technologies. The agro-geo databases are a standard environment that can be integrated into computers, Internet networks and mobile devices, as well as manage, store and edit agricultural data using ArcGIS software.
\end{abstract}

\section{Introduction}

It is important to create and visualize electronic, interactive and web maps on the basis of modern GIS (geographic information systems and technologies) of socio-economic processes in the world and its different regions. Also, one of the most important scientific and practical issues is the study of the agricultural sector, the use of cartographic support methods in the analysis $[1,2]$. In this regard, the study of agricultural, natural and socioeconomic problems related to economic development in the United States, Russia, Ukraine,

*Corresponding author: rustam.oymatov@gmail.com 
Germany, China, Vietnam and other developed countries, including the use of electronic agricultural maps to provide reliable information about the region special attention is paid to current scientific and practical issues $[2,4,6]$.

In the mapping of agricultural sectors in the world cartography pays great attention to conducting targeted research aimed at developing effective methods of data visualization and electronic mapping based on data collection, storage, analysis, processing, evaluation and creation of geodata using modern geographic information systems and technologies. In this regard, the development of modern technologies of geographic information systems and cartographic support methods is one of the important tasks in improving the method of creating electronic maps describing the agricultural sector, including taking into account the socio-economic conditions $[1,3]$.

At present, Uzbekistan is taking comprehensive measures to develop the economy and, in particular, agriculture, the rational use of natural and labor resources of the country and to improve the regional structure of the agricultural sector, taking into account the existing natural and socio-economic conditions [2]. In particular, one of the important tasks is to conduct scientific research on the cartographic support of agricultural production potential and infrastructure of the regions and the improvement of methods for creating thematic electronic maps on the basis of GIS [3, 5, 8].

Agricultural sectors, lands and infrastructure are important for Uzbekistan. Agricultural sectors and land resources are rapidly changing depending on many factors [3, 17]. Taking into account these changes, it is important to study the geographical data on agriculture, to create a regional agro-geological database in the visualization of data. Statistical, cartographic, remote sensing (RS) data are used in the creation of electronic maps of agriculture and agro-geo databases [5]. This article discusses in detail the issues of creating electronic maps of agriculture on the basis of GIS technologies and the development of technological systems for the creation of agro-geo databases [7, 8].

The research work of local and foreign scientists of Uzbekistan on the creation of agricultural maps on the basis of traditional methods and modern GIS was analyzed. Analysis of the existing scientific literature in the field shows that scientific research has been conducted in Uzbekistan, along with foreign scientists, on the cartographic study and support of problems related to the location and development of agriculture as a basic sector of the economy. Consequently, the theoretical and methodological bases of agricultural mapping have been studied by scientists from foreign and Commonwealth countries $[4,9$, $11,16]$.

Research on agricultural cartography in Uzbekistan, creation of agricultural maps using RS data and theoretical and methodological substantiation of GIS-based agricultural mapping are described in detail in the scientific works of several local and foreign scientists $[5,8,11,14]$. Without denying the results of this research, the analysis of the results of scientific and practical research in the cartographic study of agriculture in Uzbekistan shows that currently research on improving the method of creating an electronic map of agriculture, covering objects and sectors of agricultural infrastructure, depending on natural and socio-economic conditions not enough. It is also important to create an electronic agricultural map and interactive and web agricultural maps based on computer programming capabilities and agro-geo databases $[9,10]$.

As a result of scientific research of the above-mentioned scientists of Uzbekistan, the Commonwealth of Independent States and the world, maps of agriculture of various contents have been created. These maps have played an important role as an information support in economic design work in the region, rational use of land and solving problems in the field of agriculture. The scientific research carried out by the researchers is devoted to the mapping of this or that branch of agriculture $[12,13,15]$. However, the issue of creating comprehensive maps covering all sectors of agriculture and infrastructure remains one of 
the least studied areas. Research in Uzbekistan shows that the demand for maps covering all sectors of agriculture is growing significantly $[11,14]$. One of the important tasks is to create thematic maps based on the classification of agricultural maps, the development of content elements and the improvement of methods of creating electronic maps. The main objectives of this article are to create a modern scientific and methodological basis for the development of electronic mapping, a technological system of mapping of agricultural lands, as well as the creation of an agro-geological database of the region.

\section{Materials and methods}

The research is based on field work, topographic survey, statistics, ArcGIS software, cartographic materials, including electronic maps, the geographical location of agricultural networks and infrastructure facilities and their interrelationships. The technological system of electronic mapping of agriculture includes a comprehensive study of the development and use of various spatial dimensions and cartographic materials based on remote sensing data. Using these methods, it is possible to study, analyze and forecast the agricultural sector of the republic, region and district. It is aimed at developing a technological system for creating electronic maps of agriculture based on the classification of maps, analysis of content elements and the creation of GIS capabilities, RS data and agro-geo databases.

During the study, the next electronic maps in the construction of the mathematical basis for the creation of electronic maps of agriculture, "SAS. Planet" program used orthophoto plans and RS data at a scale of 1:25000.

The data collected during the field research was prepared in the form of a spreadsheet in Microsoft Excel. The main purpose of this is the ability to save the spreadsheet prepared in the program in csv (comma separated values) format. By downloading a file in this format using Global Mapper 18.2, it is possible to export a shape (.shp) file that can be imported into most GIS family software, including ArcGIS. The ability of this software (Global Mapper 18.2) to import or export files in more than 100 formats is of particular importance. In addition, another feature of the software is that the data collected on GPS receivers (coordinates, name and all features of the object) are downloaded directly to the ArcGIS program.

\section{Results and discussion}

As a result of cartographic study of agriculture and analysis of scientific works aimed at their classification, the classification of agricultural maps covering the natural conditions of the region, agricultural sectors, infrastructure facilities are proposed (Fig. 1).

As can be seen in the figure above, the classification of agricultural maps is divided into 7 sections: by creation, purpose, territorial coverage, equipment, scale, method of use, and content.

According to the results of the analysis, the system of thematic maps covering all sectors of agriculture in the region and its content elements should consist of:

- Maps of the natural conditions of the area - maps reflecting the topography, climate, precipitation, hydrography, land resources.

- Maps describing the socio-economic conditions of agriculture - Maps describing the socio-economic conditions of the rural population, agricultural production enterprises, railways, highways and other agriculture.

- Maps describing the general characteristics of agriculture and infrastructure facilities maps covering labor resources, all infrastructure facilities. 
- Agricultural mechanization maps - describe the number of agricultural machinery, maintenance and gas stations in the area.

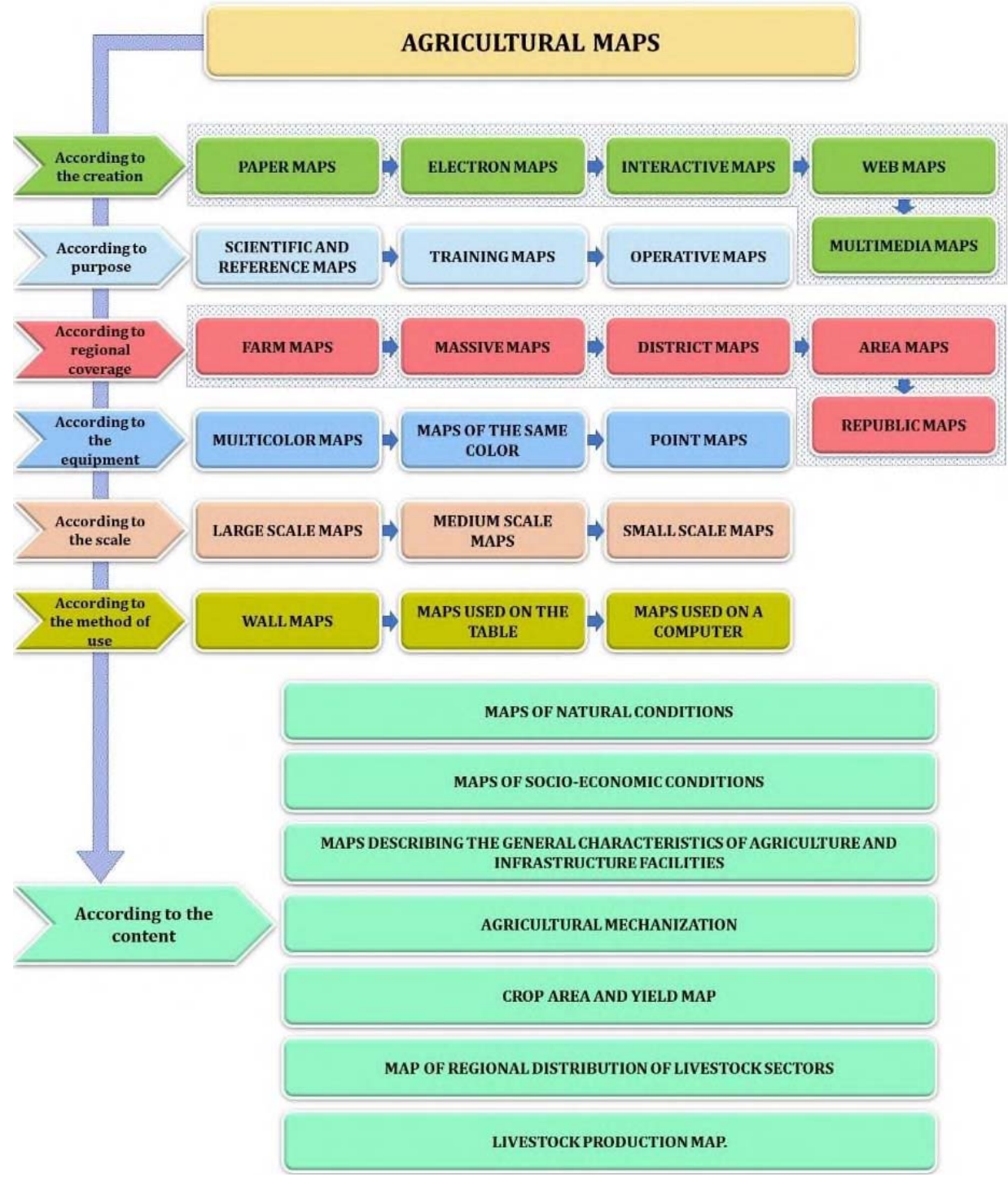

Fig. 1. Classification of agricultural maps.

- Agricultural arable land and productivity - cotton, grain, vegetables, melons, horticulture and viticulture.

- Territorial distribution of livestock industries - livestock and their distribution by pedigree, irrigation wells for poultry, beekeeping, silkworm breeding, fisheries and livestock.

- Maps of livestock production.

The developed classification is classified according to the scale, territorial coverage, purpose, method of depiction, composition, method of use and content, and as a basic proposal, the types and content of electronic, interactive, web and multimedia maps of agricultural maps cover all sectors of agriculture, natural conditions, content elements of maps covering socio-economic indicators, infrastructure facilities are proposed. As a result, 
the agricultural mapping system has made it possible to create analytical maps describing specific sub-sectors of agriculture.

Thematic maps describe not only the geographical location of events, but also their quantitative and qualitative indicators. Thematic elements (layers) of the electronic map of agriculture include groups describing the types of agricultural crops, production indicators and general characteristics and infrastructure facilities. Thematic elements of agriculture, including types of agricultural crops and their territorial distribution were determined using remote sensing materials, and production-related data were generated based on the analysis of various types of statistical data. Agricultural infrastructure facilities were mapped using field survey reports and geodetic methods.

In Fig. 2, the content elements of agriculture are divided into 7 main groups, each group in turn divided into subgroups. These thematic elements serve to fully cover the qualitative and quantitative indicators, socio-economic status of the agricultural sector in the mapped area, as well as the geographical location and other characteristics of infrastructure facilities.

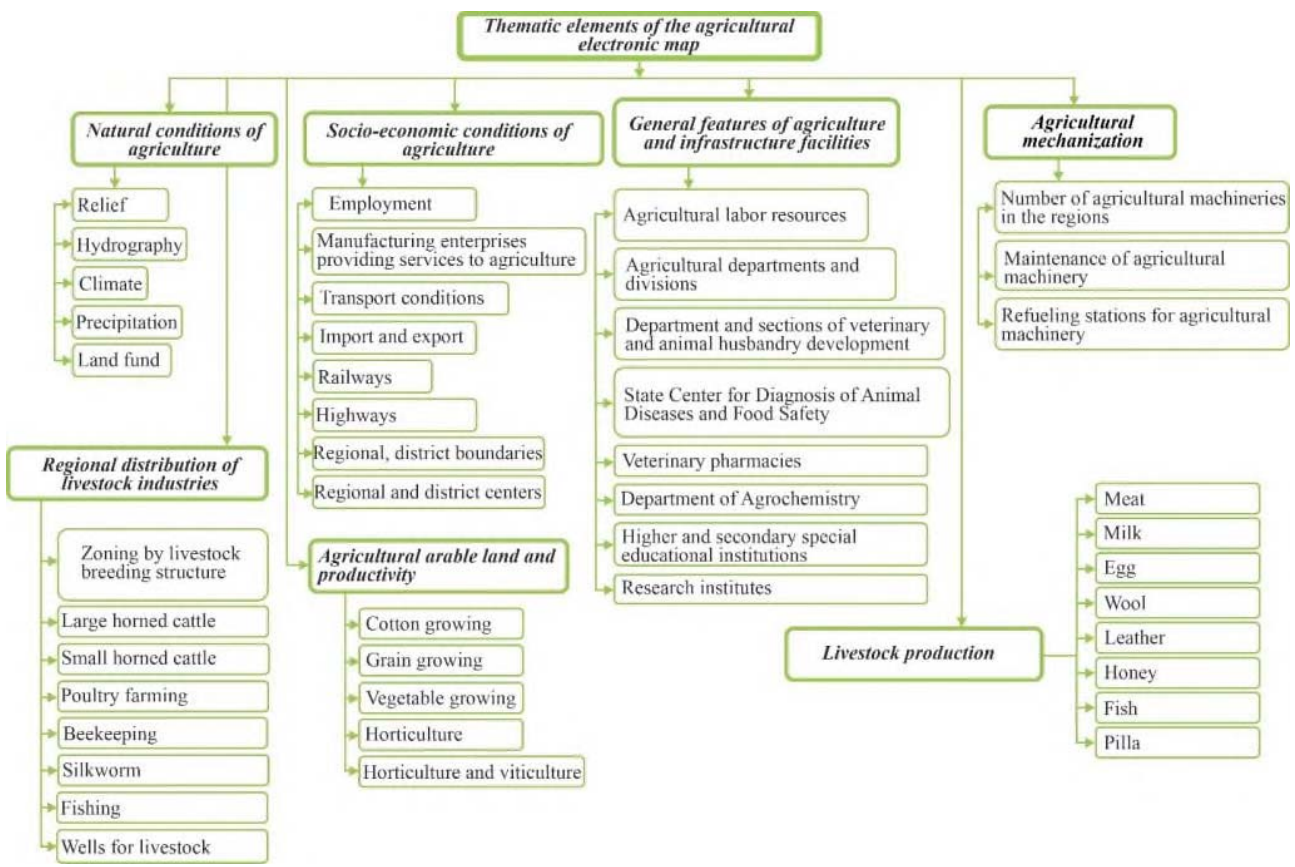

Fig. 2. Thematic elements of the agricultural electronic map.

Based on the classification of the developed maps, the content elements of the agricultural electronic map are proposed. As a result, it became possible to create analytical maps describing specific sub-sectors of agriculture.

On the basis of the content elements of the map, vector layers describing the agricultural sectors, infrastructure, natural conditions, socio-economic indicators of the mapped area are created.

During this research, the preparation for the creation of an electronic map of agriculture, field research and mapping were carried out in the following stages:

The first stage: in compiling an electronic map of agriculture, first of all, the study of qualitative and quantitative indicators of the total agriculture in the area being mapped, the analysis of previously created cartographic works, preliminary data are collected and analyzed. As a result, thematic layers (content elements) of the electronic map of 
agriculture are developed. In this process, in addition to the existing thematic layers, new content elements (layers) are added in order to analyze the quality and quantity of agricultural facilities, statistical data and their geographical distribution, assessment and forecasting for the future.

The second stage: the selection of the mathematical basis of the map is done in several ways. The process of cartographic projection and selection of other elements of the mathematical basis begins with the analysis of previously created analytical maps and their mathematical basis. In the following steps, the proposed projection in the atlases is analyzed to select the cartographic projection $[11,14]$. In this process, it is recommended to use textbooks, recommendations and manuals related to mathematical cartography.

The third stage: There are currently many types of software belonging to the GIS family for creating digital and electronic maps (Global Mapper, ArcGIS, Panorama, MapInfo, Surfer, etc.). ArcGIS software, owned by ESRI, was used to create the electronic agricultural map.

The fourth stage: field research observations will be carried out after the completion of the data entry process in terms of regional distribution of qualitative and quantitative indicators of development of all types of agricultural sectors and determining the geographical location of objects. This process mainly involves the process of determining the location of agricultural infrastructure facilities in the region through GPS (global position system) receivers and uploading them to an electronic map. During the field research, the district Department of Agriculture, Department of Veterinary and Livestock Development, veterinary pharmacies, State Center for Diagnosis of Animal Diseases and Food Safety, Department of Agrochemistry, Secondary Specialized Vocational College, maintenance of agricultural machinery and fuel the geographical location of agricultural infrastructure facilities such as injection stations was determined using a Trimble Juno 3 GPS device and mapped to an electronic map. In this process, an additional database was created based on the characteristics of each object. These data are generated on the basis of a pre-prepared record and additional data identified at the research site (Table 1).

Table 1. Example of a field account.

\begin{tabular}{|c|c|c|c|c|c|}
\hline $\begin{array}{l}\text { Status of } \\
\text { the object }\end{array}$ & Name & $\begin{array}{c}\text { Geographical } \\
\text { location }\end{array}$ & Address & $\begin{array}{l}\text { Service } \\
\text { capacity }\end{array}$ & $\begin{array}{c}\text { Additional } \\
\text { information }\end{array}$ \\
\hline 1 & 2 & 3 & 4 & 5 & 6 \\
\hline $\begin{array}{l}\text { object of } \\
\text { agricultur } \\
\text { al } \\
\text { infrastruct } \\
\text { ure }\end{array}$ & $\begin{array}{l}\text { "Guliston" } \\
\text { gas station } \\
\text { for farmers }\end{array}$ & $\begin{array}{l}6943^{\prime} \\
4253^{\prime}\end{array}$ & $\begin{array}{l}\text { R.Botirov } \\
\text { massive of } \\
\text { Alat district of } \\
\text { Bukhara } \\
\text { region }\end{array}$ & $\begin{array}{l}1500-3000 \\
\text { liters of fuel }\end{array}$ & $\begin{array}{c}\text { Tel: 8-365-34- } \\
\text { 21000 } \\
\text { Opening hours: 8: } \\
\text { 30-17: 00 } \\
\text { Leader: } \\
\text { Abdujalilov } \\
\text { Sultan }\end{array}$ \\
\hline
\end{tabular}

information is information that serves to give you a better idea of the object in the research process. This information can also consist of oral, written, and questionnaires that allow analysis and evaluation of the agricultural character of the area.

In the fifth stage, a system of symbols of the electronic map of agriculture will be developed. The structure of the system of symbols is described in 2 types. In the first round, the natural and geographical objects of the mapped area were developed using standardlooking symbols on a 1:10,000 scale plan, and thematic elements were developed using a library of symbols in the ArcGIS program.

The sixth stage. This stage includes the process of creating an electronic map of agriculture, all thematic layers of the map are loaded into the ArcGIS program, and work is 
carried out to equip the overall design elements. As mentioned above, the basis for the electronic map of agriculture is a measurement map of all types of agricultural crops for yield on irrigated arable land in the array.

When working on the design of maps, we need to pay attention to two main processes, namely: the arrangement of design elements and the process of designing the map. The design begins before a single line drawing and includes decisions on how to add information to the map, influence, scale, and select symbol types. It is at the heart of the mapping process.

Summarizing and systematizing the above steps, the technology of creating an electronic map of agriculture is formed. Based on the sequence of steps presented in this technology, a technological system for creating an electronic map of agriculture of the mapped area is formed (Fig. 3).

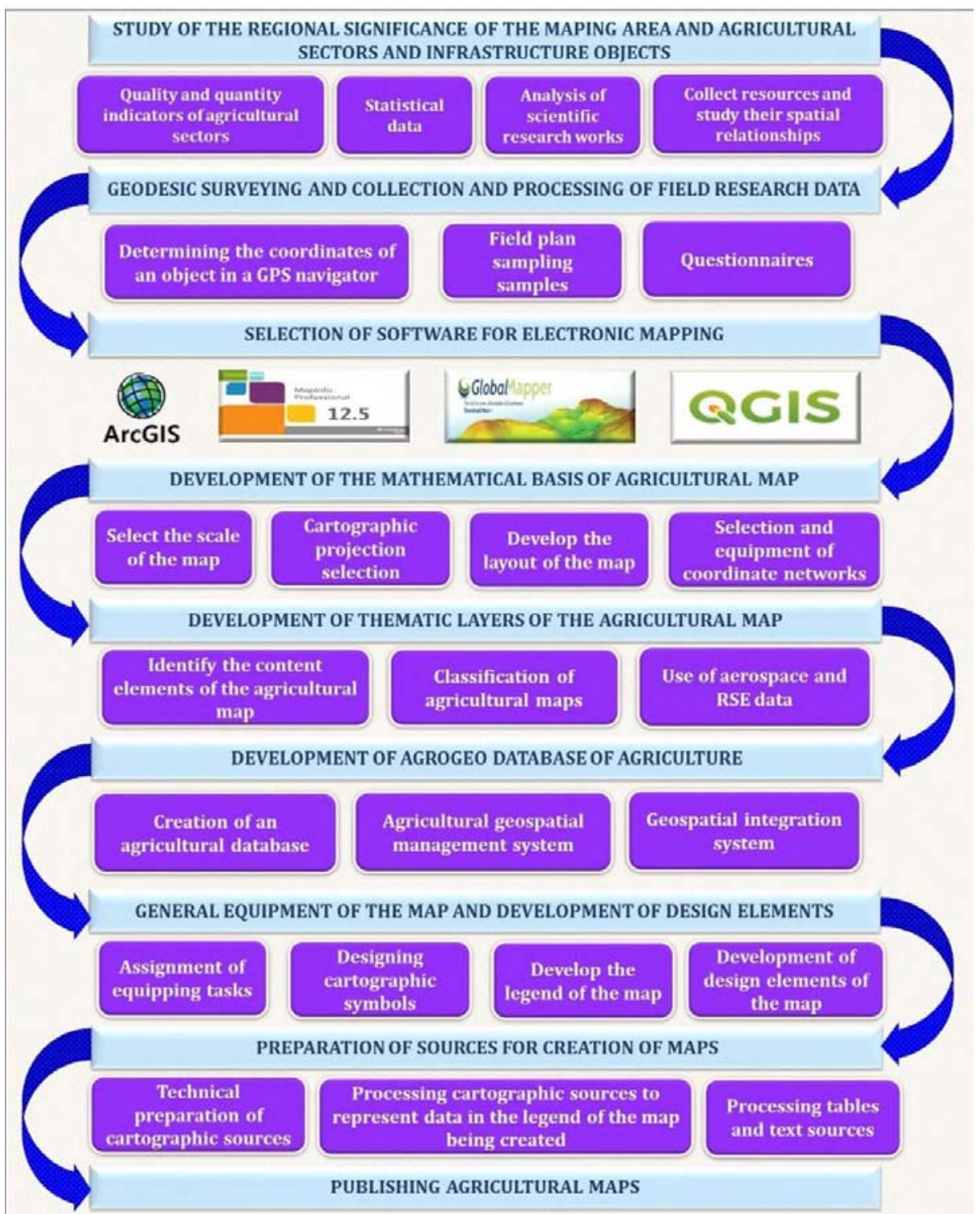

Fig. 3. Technological system for creating an electronic map of agriculture. 
Based on the "Technological system for creating an electronic map of agriculture" developed in the framework of the study, the following tasks were identified in the creation of an electronic map of agriculture in the region through the creation of an agro-geological database $[8,10]$ :

- conducting field research on modern geodetic instruments;

- creation of agro-geo databases and thematic layers;

- integration of field work into geodata;

- identification and classification of thematic layers;

- download and geophysical binding of orthophoto plans;

- vectorization of orthophoto plans and selection of symbols;

- fill in the attribute tables of thematic layers;

- Convert agro-geo databases as a basis for creating an interactive map and web map of agriculture.

Technological system of creation and conversion of agro-geo databases for the study of agricultural networks, land plots and infrastructure facilities using modern geodetic instruments in the above tasks and field exploration works (Fig. 4) was developed and the following work was carried out:

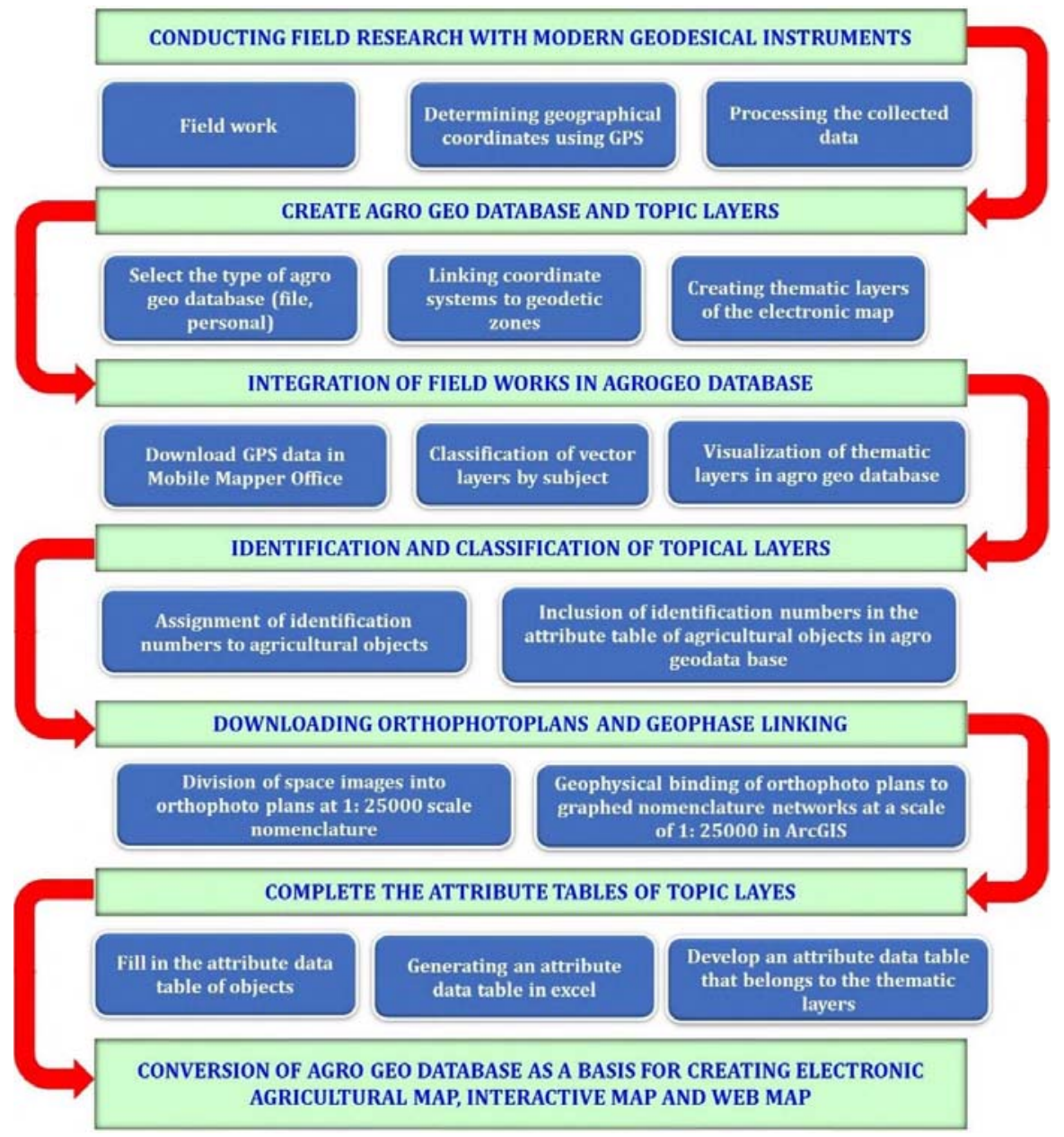

Fig. 4. Technological system of creation and conversion of agro-geo databases. 
1. Information on all objects related to agriculture, including roads, irrigation networks, land types, administrative-territorial boundaries, settlements, reliefs and markings, springs and water wells, plants, livestock and poultry, mineral fertilizer outlets, veterinary pharmacies, veterinary and livestock development centers, a complex of agricultural machinery and gas stations and food storage depots. Field research was conducted on a Magellan ProMark-3 and a Trimble Juno-3 satellite GPS receiver. Using a GPS device, turning points with each character in geographical coordinates (in the WGS-84 system), i.e. latitude $(\mathrm{g})$, distance $(\mathrm{ph})$ and height $(\mathrm{h})$, were identified in the section of agricultural objects (Fig. 5).

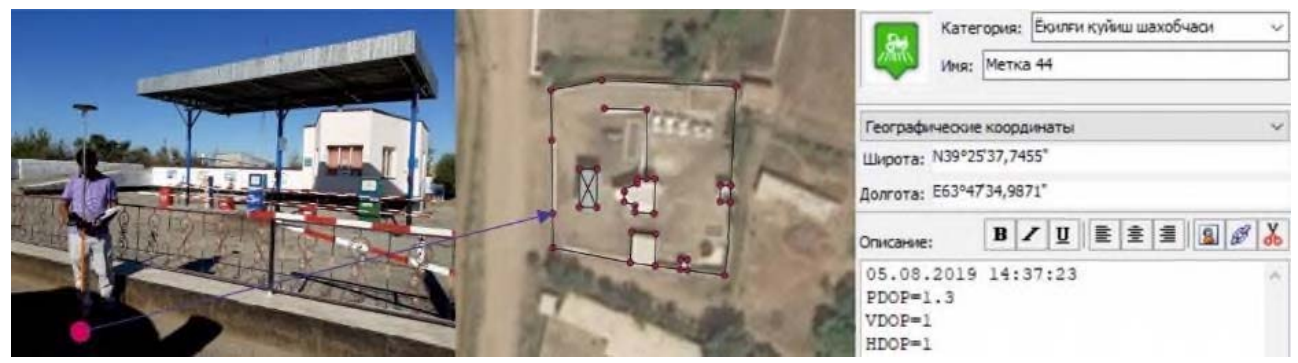

Fig. 5. The process of surveying and determining the coordinates of agricultural objects on a GPS device.

2. It is possible to know that the GPS device is in working condition after connecting to at least 4 satellites. As the number of satellites increases, so does the level of accuracy. In the Republic of Uzbekistan, Magellan's ProMark-3 GPS devices can be connected to a maximum of 12 satellites. The number of communication channels in the GPS device is 24 . The GPS device has different types of accuracy reduction, such as PDOP, VDOP, and HDOP, which is explained by a decrease in accuracy in the PDOP position, a decrease in accuracy in the VDOP vertical plane, and a decrease in HDOP in the horizontal plane (Fig. $6)$.

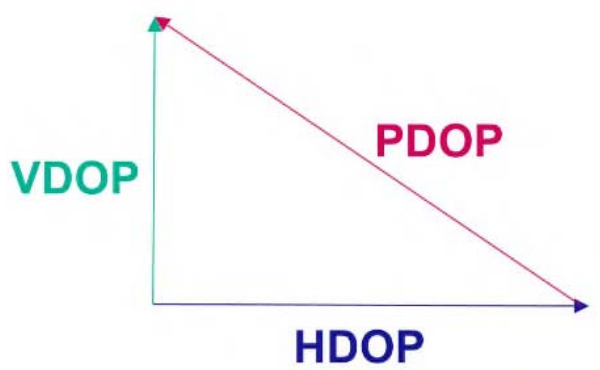

Fig. 6. PDOP, VDOP and HDOP error diagram on a GPS device.

3. The most important factor in the decrease in accuracy is PDOP, ie the increase in positioning error, and the study found that the error rate does not exceed 5 according to the geometric location of the satellites. It was found that if the positioning value exceeds 5, errors will occur in the obtained coordinate values. As a result, it was found that the coordinates of the resulting point mark can be shifted from 1 meter to 10 meters. For this reason, it is recommended to wait until the communication with the satellite improves when the PDOP position exceeds 5. Once the connections are improved, geodetic and topographic surveys will be carried out on the GPS device in linear point and area layers, and the accuracy level will be reduced from 10 centimeters to 1 meter. As a result, it 
complied with the requirement to create an electronic digital map of agriculture at a scale of 1: 25000 .

4. Based on the properties of the objects, thematic layers were selected. For example, while roads and irrigation networks are studied in a linear layer, areas that form a closed chain are studied in a linear layer. In the point layer, when entering attributive information to springs, observation wells, or objects, the area is entered with relevant data based on the point layer coordinates. Thus, the local agricultural facilities were surveyed geodetically and topographically (Fig. 7).

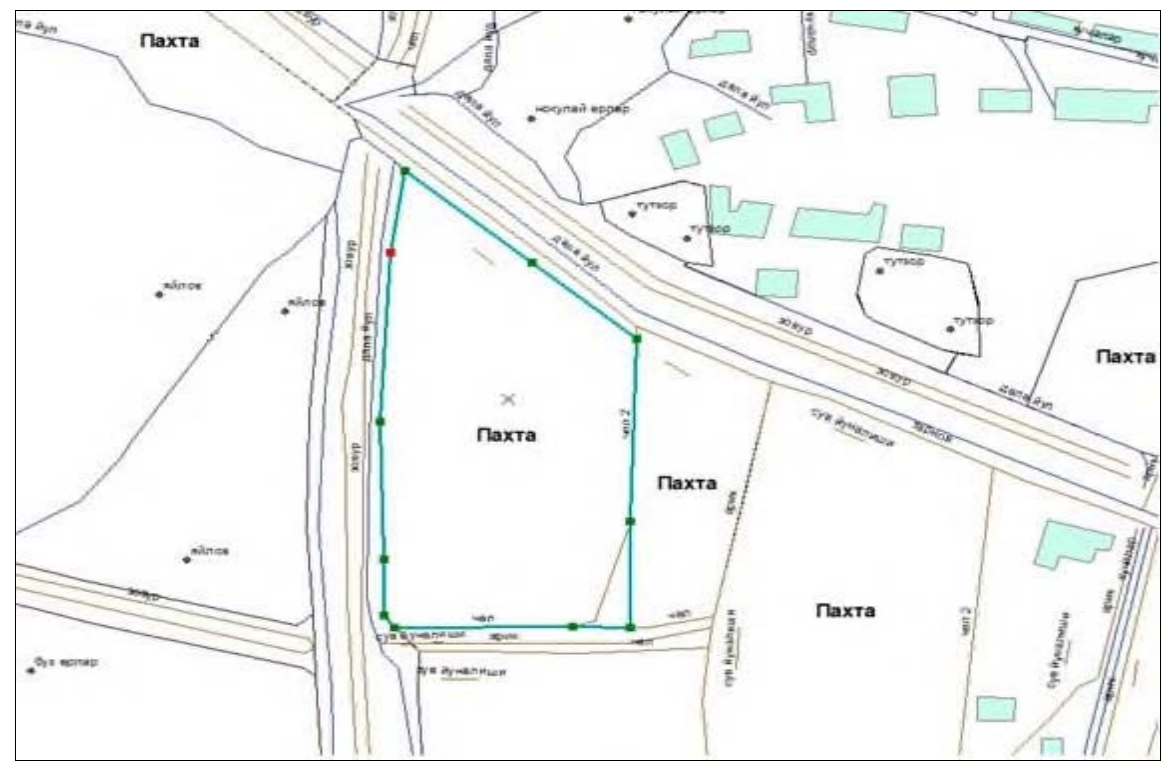

Fig. 7. Geodetic and topographic survey of agricultural facilities using a GPS device.

Field research conducted on a GPS device is stored in the memory of the device as a project. Separate projects for each agricultural object require geodetic and topographic research. It was observed in the results of the author's research that the study of a large number of agricultural objects of other types (linear, area and point) in a single project, causing projection errors in the processing of data in software. For this reason, it is recommended that a separate new project be created for each site to conduct research and that daily field research work be downloaded from the memory of the GPS device to the computer's memory. All downloaded information will be integrated into the agro-geo databases for processing.

Field research serves as a basis for the creation of agro-geo databases and thematic layers of agriculture. Based on field research, thematic themes were identified for each agricultural facility. The agro-geo databases and thematic layers were created by the author in ESRI's ArcGIS software.

The author has developed a methodology for creating an agro-geo databases and electronic digital map as a result of his field research and scientific research. The methodology of creating an agro-geo databases and thematic layers serves to achieve the following efficiency:

- Systematization of geodetic and cartographic works carried out by the relevant organizations in agriculture;

- to keep agricultural objects with unique identification numbers;

- creation and formation of electronic digital maps on the basis of a single standard;

- to maintain thematic layers of agriculture on a single standard throughout the country; 
- to provide prompt interactive services to the government on agriculture.

\section{Conclusions}

Based on the research, the following conclusions were made:

1. Foreign and Uzbek scientists have developed a classification of maps based on the analysis of research on agricultural mapping and classification, natural and climatic conditions in the region, existing industries, infrastructure facilities and the results of statistical and field research;

2. A technological system for creating an electronic map of agriculture has been created on the basis of the collection, analysis of resources used in the creation of agricultural maps and the development of a program for the creation of agricultural maps. As a result, the method of creating an electronic map of agriculture has been improved;

3. A system of electronic agricultural maps and content elements were developed, studying the features of full coverage of the agricultural sectors of the region and the interrelationships between them;

4. Technological system for creating an electronic map of agriculture and a method for creating an agro-geological database of agriculture as a result of RS data, geodetic and field surveys, analysis and processing of statistical data in the GIS. As a result, the agro-geo databases were created in an interactive, web-mapped and online platform for agricultural lands and crops, and its integration into the National Geographic Information System;

5. Based on the agro-geological database of the region, a technological system for creating an agricultural web map using the ArcGIS Online platform was created. As a result, a web map of agriculture of the Republic of Uzbekistan was developed, which provided detailed and interactive information about the natural conditions of the region, socio-economic indicators and agricultural resources and sectors, infrastructure facilities.

\section{References}

1. A. Abrosimov, B. Dvorkin, Geomatics, 4, 46-49 (2009)

2. D. Mozgovoy, O. Kravets, Ecology and noosphery, 1-2, 54-58 (2009)

3. Y. Ten, R. Oymatov, K. Khayitov, G. Saydalieva, U. Nulloev, I. Nematov, E3S Web Conf., 227, 04004 (2021)

4. O. Serebryannaya, K. Glebova, ArcReview, 4(59), 1 (2011)

5. Z. Khafizova, R. Oymatov, J. 'Agro-Ilm', 6(69), 93-95 (2020)

6. A. Cherepanov, Geomatics, 2, 98-102 (2011)

7. A. S. Babakan, Papers in Applied Geography, 4(3), 326-342 (2010)

8. B. Alikhanov, SH. Alikhanova, R. Oymatov, Z. Fayzullaev, A. Pulatov, IOP Conf. Ser.: Mater. Sci. Eng., 883(1), 012088 (2020)

9. L. Breiman, Machine learning, 45(62), 5-32, (2001)

10. CH. Conrad, S. Dech, O. Dubovyk, S. Fritsch, D. Klein, F. Loew, G. Schorcht, J. Zeidler, Computers and Electronics in Agriculture, 103, 63-74 (2014)

11. Z. Mamatkulov, E. Safarov, R. Oymatov, I. Abdurahmanov, M. Rajapbaev, E3S Web Conf., 227, 03001 (2021)

12. G. Foody, A. Mathur, Remote Sensing of Environment, 103, 179-189 (2006)

13. G. Ghazaryan, O. Dubovyk, F. Loew, M. Lavreniuk, A. Kolotii, J. Schellberg, N. Kussul, European Journal of Remote Sensing, 51(1), 511-524 (2018) 
14. B. Matyakubov, Z. Mamatkulov, R. Oymatov, U. Komilov, G. Eshchanova, InterCarto. InterGIS, 26(3), 229-239 (2020)

15. M. N. Gebeyehu, Int J Environ Sci Nat Res., 19(2), 556009 (2019)

16. K. Khakimova, I. Musaev, A. Khamraliev, E3S Web Conf., 227 (2021)

17. U. Mukhtorov, E3S Web Conf., 244, 03013 (2021) 